\title{
Ectodermal dysplasia in females and inversion of chromosome 9
}

\author{
H MORENO FUENMAYOR, * L ROLDAN-PARÍS, AND H BERMÚDEZ \\ From the Unidad de Genética Médica, Hospital Universitario, Universidad del Zulia, \\ Maracaibo, Venezuela
}

SUMMARY Absence of sweat glands, hypotrichosis, hypodontia, characteristic facial features, and $\overline{3}$ intolerance to heat, without dystrophia of the nails, are manifestations of sex linked hypohydrotic ectodermal dysplasia. Three males and two females were affected in a family in which the affected $\vec{\omega}^{\circ}$ females were also carrying a pericentric inversion of chromosome 9 . Those phenotypically normal ${ }_{N}^{\omega}$ females in this pedigree who were obligate carriers had normal karyotypes. One of the affected $\overrightarrow{+}$ females (the proband) had, in addition, primary amenorrhoea, absence of the mammary glands, 을 and rudimentery internal genitalia.

The fact that the clinical manifestations of ectodermal dysplasia in the carrier females of this family are only observed in those also carrying a pericentric inversion of chromosome 9 in peri- $\widehat{\Phi}$ pheral blood leucocytes perhaps suggests that non-random inactivation of the paternal X chromo- $\overrightarrow{0}$ some has occurred as a consequence of the inversion.

Anhidrotic ectodermal dysplasia or, more cautiously, hypohydrotic ectodermal dysplasia, is a well known syndrome. Several variant forms have been described, characterised by the presence of associated findings and different modes of inheritance. ${ }^{1}$ The most common $\mathrm{X}$ linked form is characterised by severe affection of the males with occasional minor manifestations in heterozygous females. Severe manifestations in females have been reported and explained by the unproved possible presence of a double dose of the gene. ${ }^{2}$

Pericentric inversion of chromosome 9 (inv 9) has been considered to be a non-harmful polymorphism ${ }^{3}$ with certain reservations. ${ }^{4}$ The incidence of this polymorphism varies with races but is generally around $1.5 \%{ }^{3}$

We report an unusual kindred in which several males exhibit typical anhidrotic ectodermal dysplasia, and in which in two sisters this condition occurs in association with a pericentric inversion of chromosome 9.

\section{Case reports}

CASE 1

This patient (fig 1) was referred to us at the age of 19 because of the absence of secondary sexual character-

*Present address: Department of Human Genetics, Medical Genetics Division, University of Michigan School of Medicine, Ann Arbor, Michigan 48109, USA.

Received for publication 23 May 1980

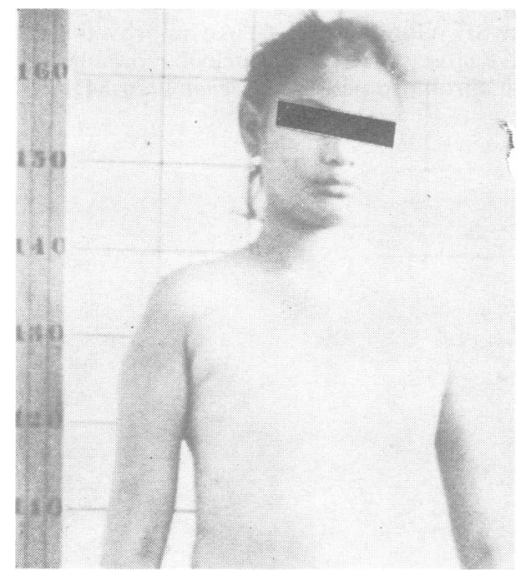

FIG 1 The proband

istics and some dysmorphic features. This subject 0 (the proband) is identified as III 3 in the pedigree $\omega$ (fig 2). Mammary glands were not developed. During infancy she was noticed to have scarcity of hair once the scalp and body, delayed eruption of teeth, and no sweating. Developmental milestones were otherwise normal. At the age of 14 , she was admitted to $\frac{0}{0}$ hospital because of fever of unknown origin, prob- $\frac{\text { Oे }}{\mathbb{D}}$ ably related to her ectodermal dysplasia. Dry skin, $\stackrel{\odot}{\oplus}$ partial alopecia of the scalp, and atrichosis of the body $\cong$ 


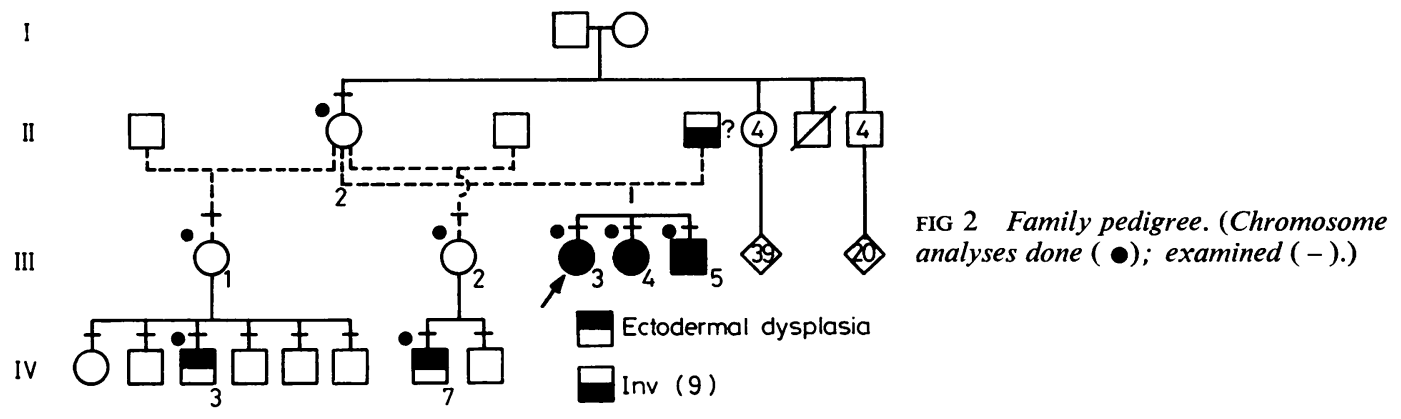

with normal development of the nails, were observed upon examination at the age of 19 . In addition, she had a depressed nasal bridge with apparent hypertelorism, absent eyebrows, rounded tip of the nose, and pouchy lips. Partial anodontia was observed as follows: $\left.\frac{8751^{*}}{8763}\right|^{1^{*}}$ (asterisks indicate conic or dysplastic teeth). The mammary glands were of infantile aspect $^{25-7}$ and sweating was diminished but not completely absent, as it was elicited in the palms and in certain areas of the arms and trunk. Body proportions were preserved, without deformities of the neck or cubitus valgus. A laparoscopic examination revealed rudimentary ovaries and uterus. A karyotype showed a pericentric inversion of chromosome 9: 46,XX, inv(9)(p13q21) (fig 3). Pores on digital epidermal ridges were examined with a dissection microscope. The number of pores per centimetre in this patient were 2 to 16 (mean of 4 ) on the right hand, and 0 to 3 (mean of 1) on the left hand. The number of pores in the mother were 16 to 18 (mean of 17). We did not find the presence of patchy areas in either of these subjects. ${ }^{89}$

\section{CASE 2}

This patient (III.5) presented the ectodermal and behavioural changes characteristic of this disorder, requiring constant bathing during the day to maintain normal body temperature. Ambulation outside the home was only possible by dressing in wet clothing. This subject did not sweat and his dentition was as follows: $\frac{752^{*} 1^{*}}{3^{*}} \mid \frac{1 * 67}{3^{*}}$. His karyotype was 46,XY,inv(9).

\section{CASE 3}

This female (III-4) was first seen by us at the age of 17. She exhibited less severe features of ectodermal dysplasia, although partial alopecia of the scalp, absent eyebrows, hypotrichosis of the body, partial anodontia, and diminished sweating with patchy

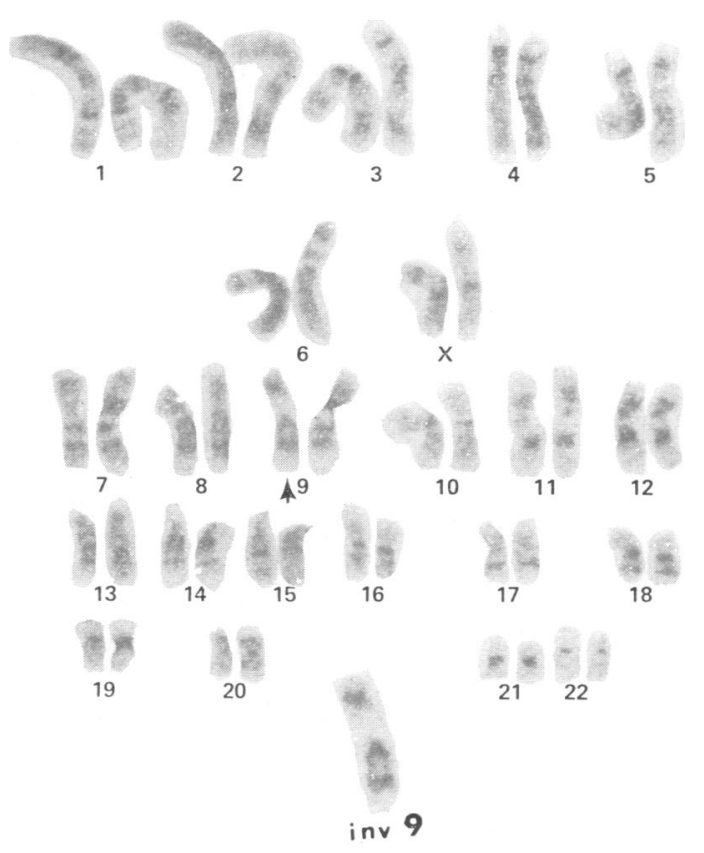

FIG 3 Karyotype of the proband showing the inv 9.

distribution were observed. She had had normal menses since the age of 13 , but development of the mammary glands was incomplete. Her karyotype was also $46, X X$, inv(9).

CASES 4 AND 5

These severely affected half-cousins (IV $\cdot 3$ and IV $\cdot 7$ ) were born to phenotypically normal half-sisters of the proband (III· 1 and III $\cdot 2$ ). IV $\cdot 7$ is the only one in whom a skin biopsy could be performed which showed a thin epidermis with few hair follicles and sebaceous glands and absence of sweat glands. Dentition in IV· 3 was as follows: $\frac{62 * 1}{6} \mid \frac{1 * 2 * 6}{\text { IV }} 7$ 
had total anodontia. The karyotypes of these two patients and their mothers were normal. Similarly, the karyotype of the mother of the proband was found to be normal.

\section{Family studies}

The mother of the proband (II-2) was the only subject from this generation with affected offspring. She reported three different biological fathers of her five children. Paternity testing could not be performed to confirm this. The father of the proband was reportedly phenotypically normal. Physical examination on obligate carriers (II $\cdot 2$, III $\cdot 1$, and III-2) failed to show any signs of ectodermal dysplasia: sweating was normal and the number of pores on the fingertips were considered to be within normal limits. Dentition seemed normal but a complete dental history could not be obtained. Their karyotypes were normal.

\section{Discussion}

Mild manifestations of $\mathbf{X}$ linked ectodermal dysplasia in females have been reported, ${ }^{10}$ but severe manifestations, as observed by Singh et al, ${ }^{2}$ have not been adequately explained. Although dominant inheritance could be claimed to explain this, the evidence for dominant mutation in this form of ectodermal dysplasia remains inconclusive. ${ }^{11}$

Inversions of chromosome 9 have been previously associated with a number of clinical problems but the relationship between these events is not clear. ${ }^{12} 13$ The pathogenic importance of the inversion is generally diminished by the fact that most carriers appear free of clinical manifestations. ${ }^{3}$

The most unusual feature of this family is the expression of ectodermal dysplasia in two heterozygous females whose mothers and half-sisters are obligate carriers and phenotypically normal. Formally, this may be explained by invoking preferential lyonisation of the normal (paternally derived) $\mathrm{X}$ chromosome in these two women. However, these subjects are also heterozygous for an inversion of chromosome 9. This gives rise to an obvious hypothesis, namely, that the two findings are not unrelated. Given these parents, the probability of a double carrier female in their offspring is $1 / 4$, and that of another carrier sister and affected brother $1 / 8$. Such an outcome would occur in $1.2 \%$ of threechildren families. No population cytogenetics data are available to calculate the probability for the incidence of severe ectodermal dysplasia in double carrier females.

Several models proposed for the genetic control of $\mathbf{X}$ inactivation require the participation of at least one autosomal locus. ${ }^{14-16}$ Condidering these models it is reasonable to postulate that mutation or position effects (related to an inverted regulatory gene) could $\stackrel{D}{\rightarrow}$ lead to an altered pattern of $X$ inactivation. We $\bar{c}$ attempted to clarify whether or not preferential $\frac{\bar{\sigma}}{\bar{\sigma}}$ inactivation of the paternal $\mathbf{X}$ chromosome had $\frac{\bar{s}}{\sigma}$ occurred in the proband. Not having the father's $\mathbb{\nabla}$ genotype, preferential inactivation of the paternal $X$ chromosome could have been ruled out had the mother been homozygous for G6PD (glucose-6phosphate dehydrogenase) and the proband hetero- $\overrightarrow{\vec{\omega}}$ zygous. However, mother and daughter expressed $\stackrel{\omega}{\sigma}$ only $\mathrm{G}^{2} \mathrm{PD}^{\mathrm{b}}$ and other relatives refused to be examined.

Other explanations cannot be disproved with the $\vec{\infty}$ information available, namely, fortuitous associa- $\omega$ tion, somatic cell selection after fertilisation, or an $\vec{N}$ unidentified 45,XO/46,XX mosaicism. This last possibility seems, however, unlikely to repeat twice $\frac{5}{5}$ consecutively and no aneuploid cells were counted $\vec{c}$ among 30 metaphases analysed per patient.

Studies involving chromosome analysis and segre- $\overparen{\varnothing}$ gation patterns of the $\mathrm{X}$ linked biochemical geno- $\overrightarrow{0}$ types (that is, G6PD) in families like this may result $\stackrel{\infty}{-}$ in contributing to our understanding of human $\mathrm{X}$ chromosome inactivation.

We thank Beverly Emanuel (University of Pennsyl- ̆ㅡㅁ vania, USA), Otto Sanchez (Universidad de Oriente, Venezuela), Karen Meilinger, and Todor Krasteff $\stackrel{\mathbb{Q}}{\square}$ (University of Michigan, USA) for assistance with $\overrightarrow{\overrightarrow{0}}$ the studies of this family; Beverly Steinke for sec- 3 retarial assistance; and J V Neel and P Smouse for $\vec{F}$ helpful comments. This work has been supported by a Universidad del Zulia (Venezuela) PostDoctoral Training Grant and the University of Michigan as a host institution.

\section{References}

1 McKusick JM. Mendelian inheritance in man. 5th ed. 0 Baltimore: Johns Hopkins University Press, 1979.

2 Singh A, Jolly SS, Kaur S. Hereditary ectodermal D dysplasia. Br J Dermatol 1962;74:34-7.

3 Lubs HA, Ruddle FH. Chromosome polymorphism in American Negro and white populations. Nature 1971; N 233:134-6.

4 Boué J, Taillemite JL, Hazael-Massieux P, Leonard C, $\stackrel{0}{\circ}$ Boué A. Association of pericentric inversions of chro- $\mathrm{N}$ mosome 9 and reproductive failure in ten unrelated $\sigma$ families. Humangenetik $1975 ; 30: 217-24$.

5 Clarke RE, McCance RA. Familial sex-linked ectodermale dysplasia with incomplete forms. Arch Dis Child 1934;9: 39-44.

6 Clouston HR. The major forms of hereditary ectodermal dysplasia (with an autopsy and biopsies on the anhidrotic type). Can Med Assoc J 1939;40:1-7.

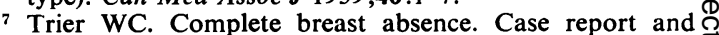
review of the literature. Plast Reconstr Surg 1965;36: 430-9. 
8 Passarge E, Fries E. X-chromosome inactivation in Xlinked hypohydrotic ectodermal dysplasia. Nature 1973; 245:58-9.

9 Filippi G, Rinaldi A, Crisponi G, Daniels GL, Siniscalco M. X-mapping in man: evidence against measurable linkage between anhidrotic ectodermal dysplasia and G6PD deficiency. J Med Genet 1979;16:223-0.

10 Pinheiro M, Freire-Maia N. Christ-Siemens-Touraine syndrome. A clinical and genetic analysis of a large Brazilian kindred. I. Affected females. Am J Med Genet 1979;4:113-22.

11 Kerr CB, Wells RS, Cooper KE. Gene effect in carriers of anhidrotic ectodermal dysplasia. J Med Genet 1966;3: 1969-76.

12 Pescia G, Gaide AC, Juillard E. Three families with pericentric inversions of chromosome 9. J Genet Hum 1977;25(2):121-34.

13 Howard-Peebles PN, Stoddard GR. Pericentric inversions of chromosome number 9: benign or harmful? Hum Hered 1979;29:111-7.

14 Lyon MF. X-chromosome inactivation and developmental patterns in mammals. Biol Rev 1972;47:1-35.

15 Brown SW, Chandra HS. Inactivation system of the mammalian X-chromosome. Proc Natl Acad Sci USA 1973;70:195-9.

16 Brown SW, Chandra HS. Chromosome imprinting and the differential regulation of homologous chromosomes. In: Goldstein L, Prescott DM, eds. Cell biology. A comprehensive treatise. vol 1, chap 4. New York, San Francisco, London: Academic Press, 1977: 110-81.

Requests for reprints to Dr H Moreno Fuenmayor, Department of Human Genetics, University of Michigan School of Medicine, Ann Arbor, Michigan 48109, USA. 